\title{
EVOLUTION OF IDEAS
}

\section{....as a source of impressive communication}

\author{
M.R. Nagajaru*
}

\section{Points to Ponder}

- Popular science communication hos to be interesting, but science teaching has to be interesting and impressive, so that the element of retention is high.

- Proof of any effective communication is active participation. This can be achieved by taking into account, the five components of communication, denoted by the acronym STEEP.

- S: Students-tèenagers

- T: Topics - Science

- E: Evaluation System

- E: Employer's needs/competitive exams

- P: Parents

All these five factors are relative and change with time.

We are considering the first two aspects in the current discussion:

\footnotetext{
* Professor of Chemistry, Government Science College Bangalore.

Chief Editor, Balavijnana, Karnatoka Rajya Vijnana Parishat, I.I.Sc., Bangalore
} 


\section{Students}

The temperament of present day students may not always be acceptable, but it is understandable.

Some visible traits in the expectations of students are:

- Adventure

- Amazement

- Amusement

- Anecodotes

- Application-oriented thinking

The current competitive examinations focus mainly on the interpretive skills and utilitarian aspects of science.

Can these be achieved within the framework of the available science curriculum? There are umpteen ways of catering to the needs listed above. A few of them are illustrated here.

Preparation for a given topic involves consideration of the six components indicated by the acronym - HELIUM.

- H: History of Science

- E: Experimental skills

- L: Logical linking

- I: Inter-disciplinary linking

- U: Utility

- $M$ : Muse

Out of these, a few aspects of evolution of ideas are dealt here: 


\section{Adventure}

- Adventures in ideas

- Adventures in experimentation

- Experiment with self

- Life risking

\section{Amazement}

- Cutting the Gordian knot

\section{Amusement}

- Fundamentals of Science are abundant with elements of fun.

- Amusing applications are also abundant

\section{Anecdotes}

- Biographies of scientists provide ample opportunities for impressive presentations.

\section{Anticipation}

- Both failure and success are scintillating and pointing.

Anxiety

- Discoveries and inventions are not cakewalks. One finds many U-turns from desperation to doubtless success.

\section{Attention}

- Keen observation of nature and review of literature provide ripe opportunities for the progress of scientific ideas.

\section{Application}

- Applications of scientific concepts are given last priority; but the current trend is to initiate the study through applications, as these are the motivating factors.

This has been taken into account in the pre-university curriculum. 


\section{Topic}

- Science is not in search of Absolute Truth. Science is in search of working models that can account for the acquired data and data that may emerge. Thus, it is a dynamic process.

- Evolution of science involves challenges, conflicts, contradictions and corrections. This obviously brings in catchy and emotional elements.

- Science communication, at present, is not participatory because of the overburdened data and the deliberate ignorance of the processes.

- Judgement communication eliminates divergent thinking and the thrill of arriving at a conclusion.

From the foregoing, we have to point out that these lacunae have led to the absence of clear thinking, scientific approach and problem-solving skills among the students of science.

Our country produces the maximum number of science graduates, but also has many prevailing superstitions. 